\title{
Research on Precision Forging Blade TENON Processing Technology
}

\author{
L.J. Huang \\ Institute of CAPP \& Manufacturing Engineering Softerware \\ Northwestern Polytechnical University \\ Xi'an, China \\ M. Kou \\ Institute of CAPP \& Manufacturing Engineering Softerware \\ Northwestern Polytechnical University \\ Xi'an, China
}

\author{
X.T. Tian \\ Institute of CAPP \& Manufacturing Engineering Softerware \\ Northwestern Polytechnical University \\ Xi'an, China \\ Z.Y. Wang \\ Xi'an Aircraft Industry (Group) Company Limited under AVIC \\ Xi'an, China
}

\begin{abstract}
TENON machining is an important and major processing for aero-engine precision forging blade. Traditional processing methods for TENON machining cannot meet the modern aero-engine performance, efficiency and environmental protection needs. In the paper, a "hard" clamping process method to machine blade TENON is proposed, and the key technologies of the method, fixture layout optimization and deformation controlling, are discussed in detail. Finally, we introduce specific scheme that designed a set of hydraulic special fixture with adaptive auxiliary support to realize "hard" clamping processing.
\end{abstract}

Keywords-aero-engine forging blade; blade TENON manufacturing; fixture layout; deformation control

\section{INTRODUCTION}

The aero-engine blade is space curved surface, and must bear complex stresses and micro vibration in working. For this reason, there is high quality requirement for blade material and machining process. Precision forging can obtain curved surface of blade with no allowance, which solve the difficulty of mechanical processing for difficult-to-machine materials and thin blade. However, blade TENON still needs mechanical processing. Blade TENON is a standard of blade design and machining, and should be machined based on blade body. Traditionally, a low-melting alloy casting process is used to machine the TENON, shown in Table 1. The alloy with low melting point is poured a square box to transform the standard of blade body into square box, and then the TENON is processed based on the surface of the square box. However, there are many disadvantages using the production process, e.g. complexpreparation, low efficiency, labor intensive, bad working conditions. In addition, the trace residue alloy can be attached on the surface of the blade in the next high temperature melting process, which would potentially impacted on the blade body surface quality.

Because of these significant technical shortcomings, a "hard" clamping process method has used to machine the TENON of precision forging blade. Compared with low melting point alloy casting process, the hard clamping process is based on the blade body direct positioning and clamping to machine, using a special fixture tool. The blade TENON is machined using milling or grinding, which positioned with three points on the body surface of the precision forging blade, two points on the intake side and one point on the bottom of the TENON, and clamped directly on the blade body. As the processing of TENON of precision forging blades is through the free-form surface of blade body to position, the main issues to be addressed include positioning, stability, clamping deformation, and repeatability etc. In the paper, we focus on the analys is of fixture layout optimization and deformation controlling issues about the "hard" clamping process, and introduce our fixture scheme.

\section{FIXTURE LAYOUT OPTIMIZATION}

Fixture layout includes location layout and clamping layout. Location layout mainly limits six freedom degrees of the part to make sure the repeatability and accuracy of positioning. Clamping layout mainly chooses the appropriate clamping position and ensures the stability of the clamp.

Based on the blade body positioning, the six points positioning method is generally used, which include the three points on the body, two points on the intake side, one point on the bottom of the blade TENON. Through the six points positioning, the blade can be completely restricted to keep the blade at the determined theoretical position. Since the blade body is free curve, easily deformed, and there are shape errors of the work piece, making it difficult to select an anchor point [1].Liu WW etc. [2], Northwestern Polytechnic University, invented a hydraulic fixture for the blade root machining of precision forging blade, located by vane basin, intake side, the inside edge of the plate, using a spring washer on the dorsal to clamp. Though the fixture is simple and easy to use, the clamping force cannot be guaranteed accurately. Al-Habaibeh A [3], Afzeri A G E [4], who designed a pin-type universal fixture system, with a clamping force evenly distributed and shape reconfigurable features. But for the distribution, diameter, length, material of 
thimble still need further study. Ma J [5] used topology optimization methods for complexfixture layout design. Y. Wang $[6,7]$ proposed a fixture layout optimization method, and considered the repeatability, stability and fixity of fixture.

\section{T ABLEI. TRADITIONAL AND NEW PROCESSINGMETHODSFOR TENON MACHINING.}

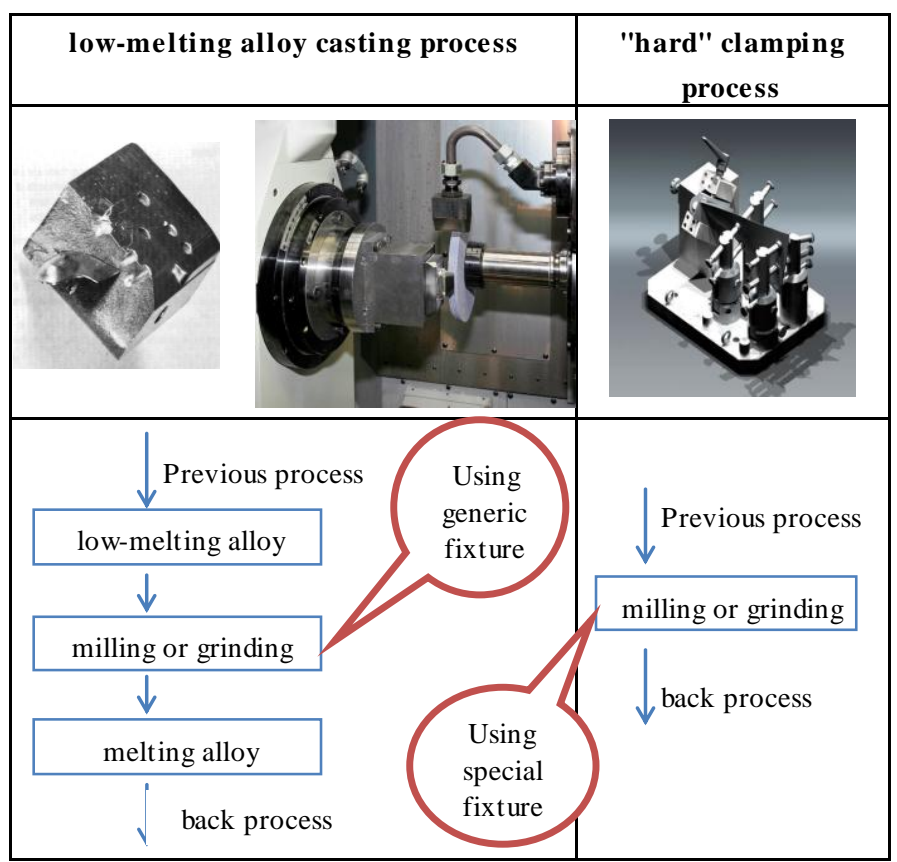

Layout optimization is based on the workpiece positioning repeatability and positioning accuracy. Clamping layout optimization provides a method for minimizing the clamping force. Clamping optimization programis as follows: 1) find ing a suitable location to ensure that does not move the clamping requirements; 2) the optimal clamping scheme between suitable clamping position and stability constraints.

\section{DEFORMATION CONTROLLING}

In actual processing, deformation of the workpiece can be divided into two types of clamping deformation and processing deformation. The former is static deformation caused by the clamping force, another is dynamic deformation caused by cutting force.

Workpiece clamping always accompanies by varying degrees of deformation. Machining accuracy is affected by the accuracy of clamping. Es pecially for weak rigid thin-walled parts, clamping deformation is more prominent, seriously affecting the machining accuracy and surface quality of the workpiece [8]. $20 \%$ to $60 \%$ is caused by a machining error of the workpiece clamping [9]. Generally deformation controlling is optimizing the clamping design. In order to control the deformation of the workpiece clamping, need to consider the clamping layout, clamping force and the order of clamping.

The main factors affect the deformation of weak stiffness workpiece are the initial stress, clamping, cutting parameters and cutting paths. Machining distortion associates with the blade structural shape, positioning and clamping layout, cutting force, cutting heat and tool path etc. In the actual process, the weak stiffness structure will exceed the difference due to the coupling effect of these factors, interaction, and error accumulating, so that difficult to control the deformation process [10]. When increased the stiffness of workpiece and fixture system, the machining deformation could be well controlled.

\section{SOLUTIONS}

According to the characteristics of the blade TENON machining, we designed a set of hydraulic special fixture with adaptive auxiliary supports. The fixture comprises positioning device, the clamping device, the auxiliary supports and control system.

\section{A. Scheme of Locating and Clamping}

The fixture scheme is shown in Figure 1. It is used six points positioning scheme for the positioning device. By analyzing the processed blade, we get six anchor points. Three positioning pins contact the blade body surface, which limit three degrees of freedom; two pins contact the intake side of the blade, limit two degrees of freedom; and the last freedom degree is limited by a pin contacting the bottom of the TENON.

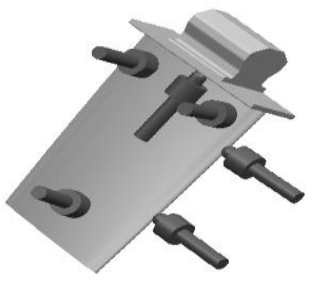

a. Positioning Model

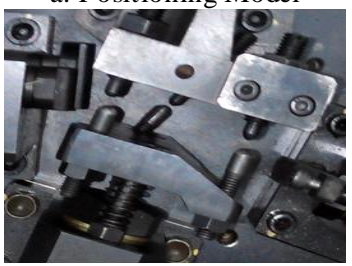

c. Fixture

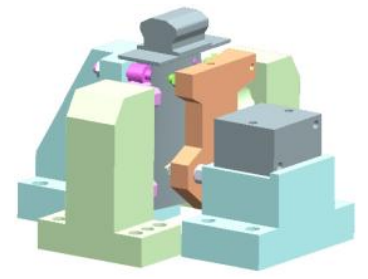

b. Fixture Model

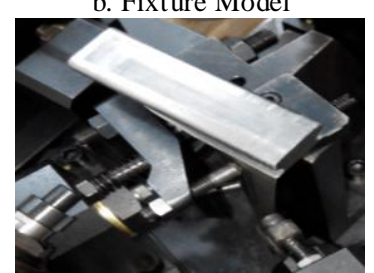

d. Example of clamping
FIGURE I. THE SCHEME OF LOCATING AND CLAMPING.

Clamping device consists of main clamping component and lateral clamping component. Main clamping component is used for clamping the body of the blade, and the latter is used for clamping the exhaust side of the blade. Both the clamping component has a hydraulic cylinder to drive the clamping block. Connecting the clamping device using a clearance fit, the device can be automatically adjusted based on the fit clearance with the clamping force, so that all three points have access to the blade's surface.

\section{B. Deformation Analysis}

We have analyzed a blade deformation under the combined effect of clamping force and cutting force using ANSYS software, shown in Figure 2. There is large deformation on the enlarged head and tip portion of the blade, but small deformation on the body portion of the blade. 


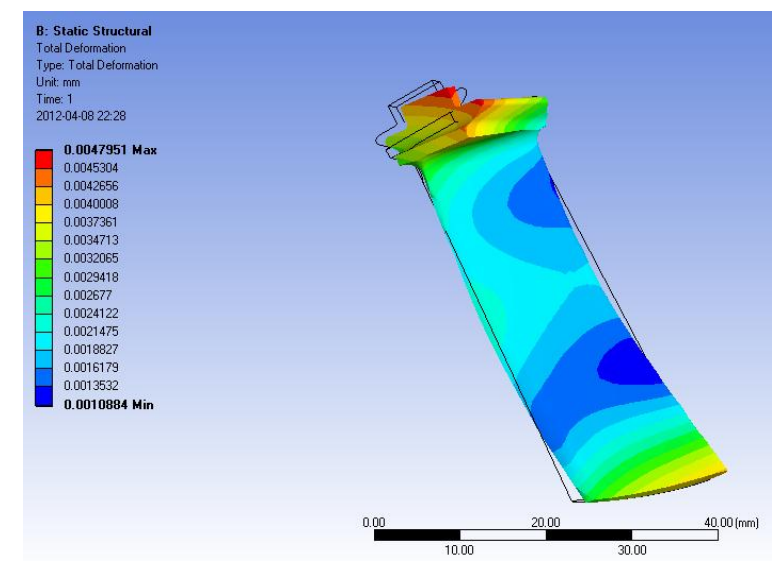

FIGURE II. DEFORMATION ANALYSIS WITH COMPREHENSIVE FORCE.

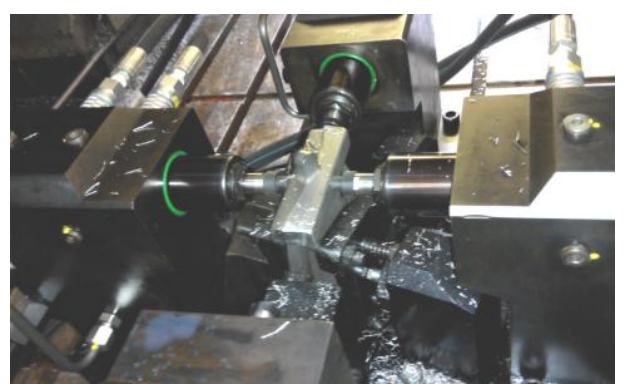

FIGURE III. COMPREHENSIVE AUXILIARY SUPPORT .

Deformation analyses are as follows:

1) Blade body deformation. The deformation of the blade comes from two aspects. One is the clamping deformation affected by the clamping force sizes, the layout of clamping points and the clamping order. The other is the process deformation, to which leaded as the reaction force from the locating and clamping pieces results local stress concentration.

2) TENON deformation caused by cutting force. When the blade TENON machined, the workpiece and fixture system is formed into a cantilever structure, and resulting in deformation under the effect of cutting force. At the same time, the change of the cutting force causes vibration, which affects the TENON processing quality seriously.

\section{Deformation Controlling}

To control the deformation of the blade TENON, we have designed a hydraulic auxiliary support device. The auxiliary supports provide reaction force against the cutting force, increase the workpiece stiffness and reduce the clamping force to ease clamping deformation. The auxiliary support device, shown in Figure 3, includes four auxiliary support mechanis ms disposed opposite. Wherein the supports driven by cylinder adaptively contact the surface of TENON and locked. When one side of the TENON machined, the supporting head is retracted to the side, but the corres ponding head supports. With this manner, the position of the blade can be maintained without excessive positioning. The stiffness of the thin-walled blade can be greatly improved, and the clamping force apply to the blade can be reduced to control clamping deformation.
In order to avoid the cutter interference with the supports, we have designed a set of controller. The controller communicates with the programmable logic controller of the machine tool and hydraulic controlvalves, in order to obtain the tool position data from the numerical control system in real time and to control to retract or support. Each auxiliary support head is adjusted by built-in algorithms according to the cutting tool path, to avoid the interference and make the machining process smoothly.

\section{CONCLUSION}

In the paper, we study machining process of the no margin forging blade TENON, propose a new type of TENON processing scheme with positioning and clamping the blade directly, multi-directional auxiliary support for the TENON with digital control of hydraulic system. The advantages of the new technology are as follows:

1) Positioning and clamping against the thin curved blade directly, and removing low melting point alloy casting and melting processes, the blade machining process chain is dramatically shorten.

2) The design of the adaptive auxiliary support device is used to remain the support in contact with the blade TENON, and the blade position can be maintained without excessive positioning. Therefor the machining deformation can be effectively reduced, and the processing quality improved.

\section{REFERENCES}

[1] Vishnupriyan S, Majumder M C, Ramachandran K P. Optimal fixture parameters considering locator errors. International Journal of Production Research, 2011, 49(21): 6343-6361.

[2] Liu W W, Wan X S, etc. Forging the blade root machining hydraulic TENON jig. China Patent, CN CN102615534B. 2013.11.06

[3] Al-Habaibeh A, Gindy N, Parkin R M. Experimental design and investigation of a pin-type reconfigurable clamping system for manufacturing aerospace components. Proceedings of the Institution of Mechanical Engineers, Part B: Journal of Engineering Manufacture, 2003, 217(12): 1771-1777.

[4] Afzeri A GE, Sutjipto A K M, Nurul Amin R M. Determination of pin configuration for clamping fixture by means of solid model contact analysis.//Proceedings of the International Conference on Mechanical Engineering (ICME), Dhaka, Bangladesh. 2005.

[5] Ma J, Wang M Y, Zhu X. Compliant fixture layout design using topology optimization method.//Robotics and Automation (ICRA), 2011 IEEE International Conference on. IEEE, 2011: 3757-3763.

[6] Wang Y, Chen X, Liu Q, et al. Optimisation of machining fixture layout under multi-constraints. International Journal of Machine Tools and Manufacture, 2006, 46(12): 1291-1300.

[7] Wang Y, Chen X, Gindy N, et al. Elastic deformation of a fixture and turbine blades system based on finite element analysis. The International Journal of Advanced Manufact uring Technology, 2008, 36(3-4): 296-304.

[8] Wu N H, Chan K C, Leong S S. Static interactions of surface contacts in a fixture-workpiece system. Internal Journal of Computer Applications in Technology, 1997, 10(3/4):133-151.

[9] Qin, G H, Wu, Z X, Zhang, W H. Analysis and control technique of fixturing deformation mechanism of thin-walled workpiece. Jixie Gongcheng Xuebao. 2007, 43(4): 211-216.

[10] Lu D. Deformation Prediction and Fixture Layout Optimization of Aerospace monolithic components. Jinan, China: Shandong University, 2007. 